\title{
An overview of groundwater chemistry studies in Malaysia
}

\begin{abstract}
In this paper, numerous studies on groundwater in Malaysia were reviewed with the aim of evaluating past trends and the current status for discerning the sustainability of the water resources in the country. It was found that most of the previous groundwater studies (44\%) focused on the islands and mostly concentrated on qualitative assessment with more emphasis being placed on seawater intrusion studies. This was then followed by inland-based studies, with Selangor state leading the studies which reflected the current water challenges facing the state. From a methodological perspective, geophysics, graphical methods, and statistical analysis are the dominant techniques $(38,25$, and $25 \%$ ) respectively. The geophysical methods especially the 2D resistivity method cut across many subjects such as seawater intrusion studies, quantitative assessment, and hydraulic parameters estimation. The statistical techniques used include multivariate statistical analysis techniques and ANOVA among others, most of which are quality related studies using major ions, in situ parameters, and heavy metals. Conversely, numerical techniques like MODFLOW were somewhat less admired which is likely due to their complexity in nature and high data demand. This work will facilitate researchers in identifying the specific areas which need improvement and focus, while, at the same time, provide policymakers and managers with an executive summary and knowledge of the current situation in groundwater studies and where more work needs to be done for sustainable development.
\end{abstract}

Keyword: Groundwater; Hydrochemistry; Island; Malaysia; Quality; Quantity; Review 